\title{
IS/IT Strategic Planning Pada Universitas Balikpapan
}

\author{
Anwar Fattah \\ Teknik Elektronika \\ Politeknik Negeri Balikpapan \\ Jln. Soekarno-Hatta Km 8, Balikpapan 76127, Indonesia \\ Anwar.fattah@gmail.com \\ A.Asni B \\ Teknik Elektro \\ Universitas Balikpapan \\ Jln. Pupuk Raya,Gn.Bahagia, Balikpapan 76114, Indonesia
}

\begin{abstract}
The purpose of this research is to analyze business environment and IS/TI. In University balikpapan in which the method in use are with through interviews, kuisioner and observation in the university of balikpapan With a method of strategic planning it / is (ward \& peppard, 2002) in get a picture of the environment actually business. The analysis of the research strategy it produces output in the form of IT division, that is an application that need to support business, the needs of technology and human resources support an application in portfolio days are future. From our analysis in do strategic planning can be concluded that the university of balikpapan are arranged in this research become a reference for the development of the SI/TI Strategic Planning supporting the process of business lie at the university of balikpapan.
\end{abstract}

Keywords : Strategy Planning, Strategy

\begin{abstract}
Abstrak
Tujuan dari penelitian ini adalah untuk menganalisis lingkungan bisnis dan IS/IT yang ada di Universitas Balikpapan di mana metode yang di pakai adalah dengan melalui wawancara, kuisioner dan observasi di Universitas Balikpapan. Dengan metode Strategic planning IT/IS (Ward \& Peppard,2002) di peroleh gambaran lingkungan bisnis yang sebenarnya. Hasil analisis dari penelitian ini menghasilkan keluaran berupa strategi divisi IT, yaitu aplikasi yang di butuhkan untuk mendukung bisnis, kebutuhan teknologi dan sumber daya manusia yang mendukung portofolio aplikasi di masa

akan datang . dari analisis yang di lakukan dapat di simpulkan bahwa Perencanaan strategis SI/TI Universitas Balikpapan yang disusun dalam penelitian ini menjadi acuan bagi pengembangan SI/TI dalam menunjang proses bisnis yang ada di universitas balikpapan
\end{abstract}

Kata kunci : Perencanaan Strategi, Strategi

\section{Pendahuluan}

Teknologi Informasi (IT ) sangat berperan penting dalam mendukung untuk kegiatan harian dan memiliki peran yang sangat strategi secara organisasi dan investasi. Pada bidang organisasi, IT sangat berperan secara signifikan, baik pada desain usaha, kondisi kerja karyawan dan kinerja ekonomi. Hal ini telah mengakibatkan pengambilan keputusan IT menjadi salah satu tindakan yang paling penting dalam organisasi. Saat ini, sistem dan teknologi informasi telah berkembang dengan pesat, dimana perkembangan ini membawa dampak dan perubahan ke berbagai bidang salah satunya adalah bidang Pendidikan. Para Penyelenggara Pendidikan terutama institusi perguruan tinggi dan politeknik dituntut oleh pemerintah dan stakeholder (Perusahaan/Industri) untuk mempersiapkan sumber daya manusia yang berkompeten agar mampu bersaing di era globalisasi baik itu dosen, mahasiswa maupun semua pihak 
yang terlibat didalamnya. Saat ini Universitas Balikpapan memanfaatkan Teknologi informasi dalam melakukan proses bisnis organisasi, agar tetap bertahan dalam persaingan dari berbagai perguruan tinggi negeri ataupun swasta lainnya serta dapat tumbuh berkembang menjadi institusi pendidikan yang besar.

Pengembangan

dan

implementasi SI/TI pada organisasi di landasi oleh sebuah perencanaan strategis teknologi informasi yang matang. mengingat dampak dari perencanaan Strategi Manajemen SI/IT ini akan sangat berdampak bagi perencanaan strategi SI/IT seperti tidak sejalan dengan tujuan strategis organisasi, tidak adanya master plan teknologi informasi, tidak tersedianya alokasi biaya untuk penerapan SI/TI, tidak adanya standarisasi pengukuran kualitas SI/TI dan lain lain.

Universitas Balikpapan masih tahap pengembangan dan implementasi SI/TI, tapi terjadi kesalahan-kesalahan konsep sehingga SI/IT yang ada menjadi tidak seperti yang di inginkan dan terjadi banyak kelemahan-kelemahan sehingga aktivitas kampus mengenai segala bentuk yang berhubungan dengan SI/IT menjadi tidak maksimal disebabkan tidak adanya perencanaan strategis teknologi informasi. Perencanaan yang ada selama ini tidak seluruhnya mengacu kepada visi, misi, dan sasaran/tujuan Universitas Balikpapan, sehingga ketika pengajuan rencana kerja menjadi tidak efektif.

Oleh karena itu peneliti membahas mengenai perencanaan strategis SI/TI yang disesuaikan dengan visi, misi, sasaran/tujuan dan proses bisnis yang ada di Universitas Balikpapan. Sehingga dapat memberi gambaran ke depan terhadap pengembangan SI/TI di Universitas Balikpapan.
Dari latar belakang penelitian tersebut maka terdapat permasalahan utama dimana belum adanya kerangka acuan perencanaan strategis SI/TI di Universitas Balikpapan yang sejalan dengan visi, misi, sasaran/tujuan dan proses bisnis yang ada di Universitas Balikpapan, sehingga dengan adanya perencanaan strategis SI/TI nantinya membawa nilai tambah bagi sebuah Universitas Balikpapan untuk dapat berjalan selangkah lebih maju dibandingkan universitas lainnya serta pedoman dalam melakukan perancangan dan pengembangan SI/TI di masa mendatang.

Tujuan utama dari penelitian ini adalah untuk melakukan perencanaan strategis SI/TI yang disesuaikan dengan visi, misi, sasaran/tujuan, dan proses bisnis di Universitas Balikpapan.

\section{Metode Penelitian}

Metodologi yang digunakan dalam penulisan ini adalah dengan pendekatan studi kasus, analisis dan evaluasi dengan studi literature terhadap dokumen-dokumen organisasi berkenaan dengan strategi organisasi, rencana manajerial dan operasional, dan penggunaan sistem informasi dan teknologi informasi yang ada pada organisasi. Penyusunan metodologi mengacu metodologi yang dibuat oleh (Ward \& Peppard, 2002) dalam bukunya Strategic Planning for Information Systems. 


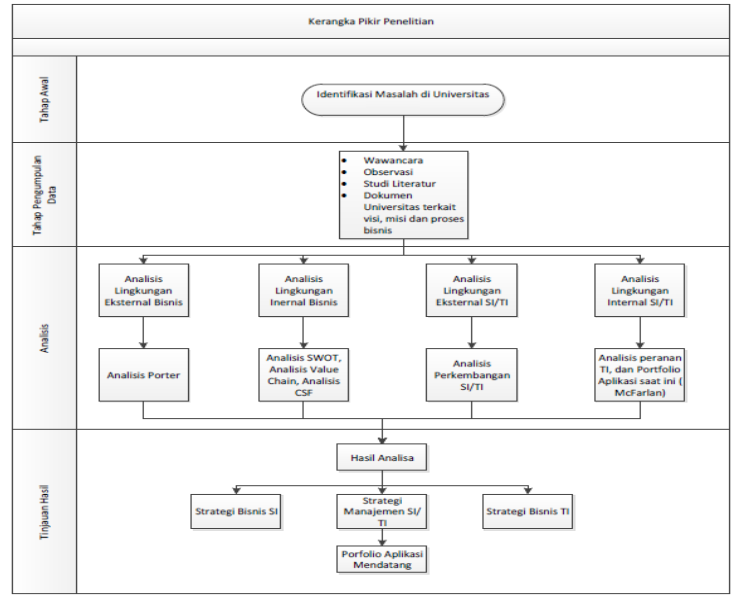

Gambar 1. Metodologi Perencanaan Strategi IS/IT (Ward \& Peppard, 2002)

\section{Hasil Penelitian}

Universitas Balikpapan (Uniba) sejauh ini telah mengimplementasikan berbagai inisiatif dan inovasi Sistem Informasi dan Teknologi informasi (SI/TI) yang menunjang proses perkuliahan sebagai kegiatan utama maupun beberapa kegiatan penunjang lainnya. Secara umum, Uniba telah mulai memanfaatkan SI/TI dalam pelaksanaan operasionalnya.

Dalam Rencana Strategis Universitas Balikpapan Tahun 20102014 telah dicanangkan sasaran-sasaran mutu yang menempatkan SI/TI tidak hanya sebagai pendukung proses kegiatan, tetapi SI/TI diharapkan sebagai enabler dari proses kegiatan tersebut. Terkait dengan rencana besar ini, dirasakan perlu untuk mensistematiskan berbagai implementasi SI/TI saat ini dan yang akan datang secara lebih terstruktur, sehingga arsitektur SI/TI benar-benar dapat memberikan peningkatan Universitas sebagai sebuah Institusi pendidikan tinggi.

\section{Analisis Lingkungan Eksternal Bisnis Universitas}

Analisis ini merupakan analisis terhadap faktor-faktor eksternal yang mempengaruhi strategi bisnis pada universitas, baik peluang maupun ancaman bagi perusahaan.

\section{Analisis Lima Daya Porter (Porter's Five Forces)}

Dalam menganalisis situasi lingkungan eksternal yang mungkin di hadapi di gunakan teknik analisis eksternal dengan menggunakan model porters Five Forces. Menggunakan 5 (lima) kekuatan yang mempengaruhi posisi Universitas Balikpapan dalam meningkatkan kemampuan institusi pendidikan tinggi dalam menangkap peluang positif serta peningkatan competitive advantage.

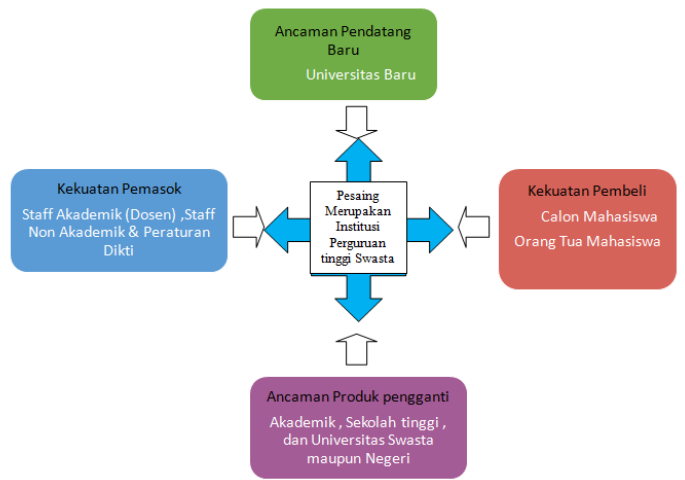

Gambar 2. Analisis Lima Daya Porter Universitas Balikpapan

\section{Analisa Lingkungan Internal Bisnis Universitas}

Dalam rangka pencapaian visi dan misi serta tujuan perlu adanya rumusanrumusan strategis yang tepat, untuk dapat menilai, memerlukan beberapa pendekatan internal dengan mempertimbangkan faktor kelemahan dan kekuatan, sedangkan pendekatan eksternal dengan mempertimbangkan faktor peluang dan ancaman. Untuk mendiskripsikan hal tersebut diatas, diperlukan analisis SWOT . Adapun analisis lainnya menggunakan pendekatan Analisa Critical Success Factor (CSF) dan Analisa Value Chain. 


\section{Analisa SWOT}

Analisis SWOT Universitas Balikpapan melalui serangkaian Uji Reabilitas dan Uji Validitas. Berdasarkan pengujian tersebut maka berikut hasil analisis SWOT untuk selanjutnya diolah ke dalam tabel perhitungan IFAS (Internal Strategic Factors Analysis Summary) dan tabel EFAS (External Strategic Factors Analysis Summary).

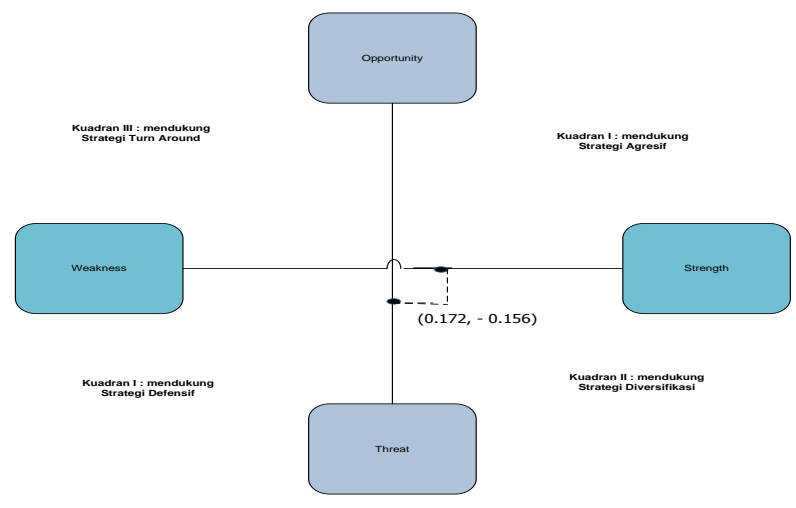

Gambar 3. Analisis SWOT

Dapat dilihat dari gambar diatas bahwa posisi relatif Universitas Balikpapan terletak pada koordinat $(0.172,-0.156)$, yang berarti pada posisi tersebut telah menempatkan Universitas Balikpapan pada Kuadran II, oleh karena itu strategi yang diambil adalah "Mendukung Strategi Diversifikasi".

\section{Analisis CSF}

Dari Tujuan yang akan dicapai Universitas Balikpapan yang sesuai dengan visi, misi dan fungsi universitas. Implementasi tujuan tersebut akan dilaksanakan oleh unit-unit kerja di Universitas Balikpapan. Penjabaran tujuan utama Universitas Balikpapan menjadi tujuan setiap unit satuan kerja.

\section{Analisis Value Chain}

Analisis ini bertujuan untuk mengidentifikasi aktivitas yang di lakukan universitas yang terbagi atas dua aktivitas, yakni aktivitas primer dan aktivitas sekunder. Berdasarkan dokumen SPM-PT (Sistem Penjamin Mutu Perguruan Tinggi ) yang dikeluarkan oleh Direktorat Jenderal Pendidikan Tinggi, aktivitas primer universitas terbagi atas 3 yaitu pengajaran, penelitian, dan pengabdian kepada masyarakat yang di sebut Tri Dharma Perguruan Tinggi .

Gambar 4. Analisis Value Chain

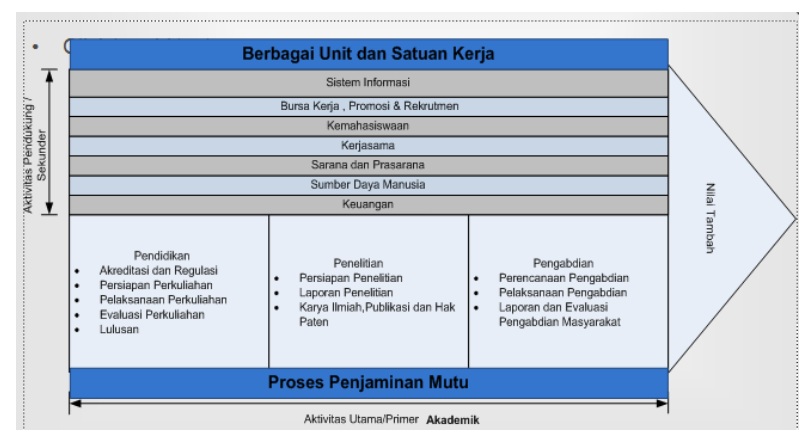

\section{Analisa Lingkungan Eksternal SI/TI organisasi}

Dalam menganalisa lingkungan eksternal SI/TI akan di paparkan tinjauan terhadap tren teknologi yang berkembang saat ini. Berdasarkan Tren IT yang mendominasi menurut Gartnet (Top 10 Strategic Technology Trends for 2015). Terdapat 10 tren teknologi yang memiliki potensi yang dapat mempengaruhi individu, bisnis, dan organisasi TI.

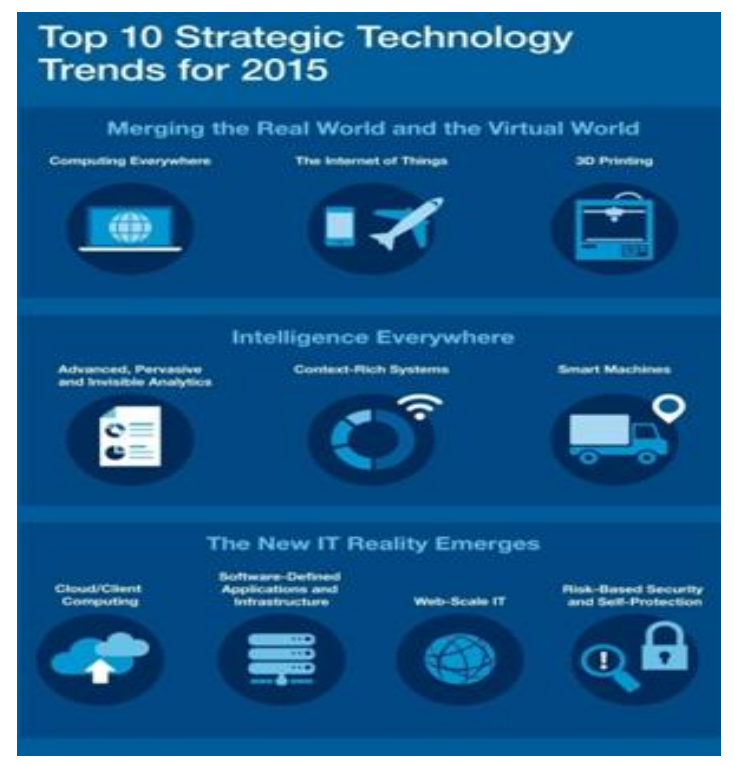


Analisa Lingkungan Internal SI/TI Organisasi

Portofolio Aplikasi Saat Ini (McFarlan Strategic Analysis)

Analisis Aplikasi Portofolio Bisnis McFarlan dapat digunakan untuk memetakan aplikasi yang ada saat ini dan juga kebutuhan aplikasi di masa akan datang dalam mendukung bisnis organisasi. Pemetaan aplikasi ini dengan empat kuadran: strategic, high potential (turnaround), key operation (factory), dan support, sesuai kategori penilaian suatu aplikasi terhadap dampaknya terhadap bisnis.

Tabel 1. Kategori Aplikasi saat ini pada Universitas Balikpapan

\begin{tabular}{|c|c|c|c|}
\hline$y$ & & Strategic & High Potential \\
\hline 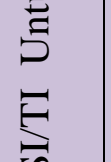 & 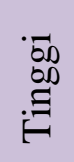 & SIMAS & $\begin{array}{l}\text { Website Uniba } \\
\text { Jurnal Uniba } \\
\text { Opac/Simprus }\end{array}$ \\
\hline & & Key Operation & Support \\
\hline 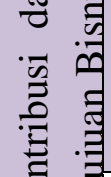 & 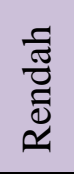 & & $\begin{array}{l}\text { SCL Learning } \\
\text { CDC } \\
\text { Unimax Staff }\end{array}$ \\
\hline $1:$ & & Tinggi & Rendah \\
\hline 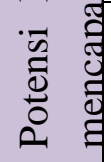 & & \multicolumn{2}{|c|}{$\begin{array}{l}\text { Ketergantungan } \\
\text { Keberlangsungan } \\
\text { terhadap SI/TI }\end{array}$} \\
\hline
\end{tabular}

\section{Infrastruktur Jaringan TI}

Berikut adalah gambaran dari Topologi jaringan Universitas Balikpapan

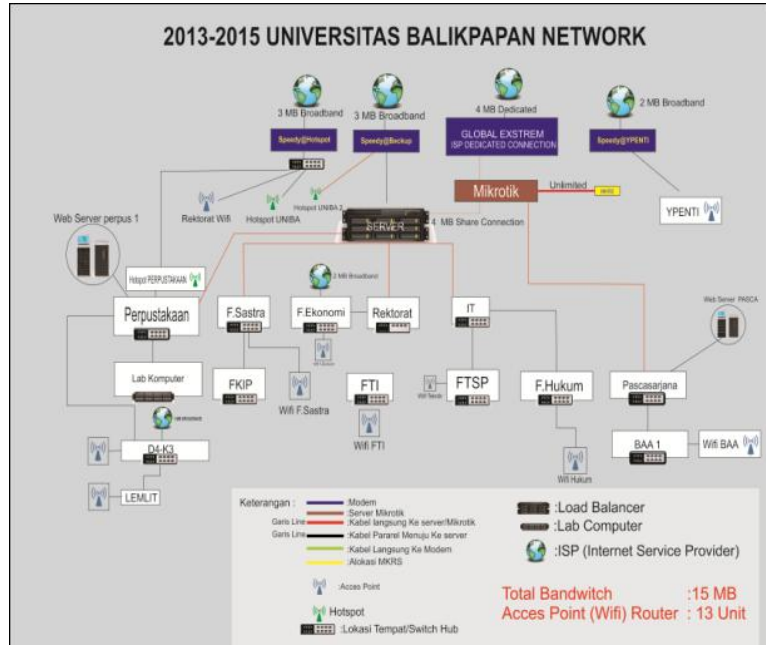

Gambar 6. Infrastruktur Jaringan TI

\section{Perencanaan Strategi SI}

Perencanaan Strategi SI untuk memperoleh solusi sistem informasi termasuk teknologi yang terdapat didalamnya. Solusi SI yanag di usulkan mendukung visi, misi dan proses bisnis di Universitas Balikpapan. Dari sini Solusi SI ini diidentifikasi berdasarkan analisis yang telah ada.

Tabel 2. Peta Aplikasi SI Masa Akan datang

\begin{tabular}{|c|c|c|c|c|c|}
\hline \multirow{5}{*}{ 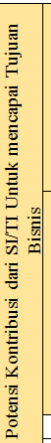 } & & Strategic & & High Potential & \\
\hline & 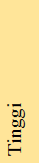 & $\begin{array}{l}\text { SIMAS (SI Akademik) } \\
\text { Jurnal Uniba (SI } \\
\text { penelitian } \\
\text { Pengabdian,dan } \\
\text { publikasi Ilmiah) }\end{array}$ & $\begin{array}{l}\text { Upgrade } \\
\text { Upgrade }\end{array}$ & $\begin{array}{l}\text { Website Uniba } \\
\text { Opac/Simprus (perpustakaan) } \\
\text { Uniba Mobile }\end{array}$ & $\begin{array}{l}\text { Ada } \\
\text { Ada } \\
\text { Baru }\end{array}$ \\
\hline & & Key Operation & & Support & \\
\hline & & SCL Learning & Ada & $\begin{array}{l}\text { Carrier Developmen } \\
\text { Center(SI Alumni \& karir) } \\
\text { Unimax Staff (SI } \\
\text { kepegawaian) } \\
\text { SI Asset \& Inventory } \\
\text { SI Akuntansi dan Keuangan } \\
\text { SI pengadaan } \\
\text { SI Hibah dan Kerjasama }\end{array}$ & $\begin{array}{l}\text { Upgrade } \\
\text { Ada } \\
\text { Baru } \\
\text { Baru } \\
\text { Baru } \\
\text { Baru }\end{array}$ \\
\hline & & Tinggi & & Rendah & \\
\hline
\end{tabular}

\section{Perencanaan Strategi TI}

Dalam pembuatan IS/IT Strategic Planning, dibuatlah usulan perencanaan strategi teknologi informasi yang akan digunakan kedepannya, sehingga semua usulan sistem informasi dapat berjalan dengan baik. Usulan teknologi informasi ini menjelaskan mengenai usulan infrastruktur jaringan yang baru. 
Arsitektur Teknologi Informasi (TI)

Untuk dapat mendukung aplikasi/Sistem informasi yang di hasilkan di atas, maka di perlukan arsitektur teknologi informasi yang dirancang menghadapi perkembangan aplikasi/sistem informasi Uniba kedepan.

Arsitektur sistem memberikan deskripsi tentang lapisan-lapisan logikal yang membentuk sistem TIK Uniba secara keseluruhan, yaitu lapisan presentasi, lapisan aplikasi, lapisan data dan lapisan dasar. Cara pandang ini akan membantu Uniba dalam mengalokasikan sumberdayanya, sekaligus sebagai panduan dalam menetapkan standarisasi teknologi melalui penyediaan framework-framework sebagai model untuk setiap lapisan secara spesifik

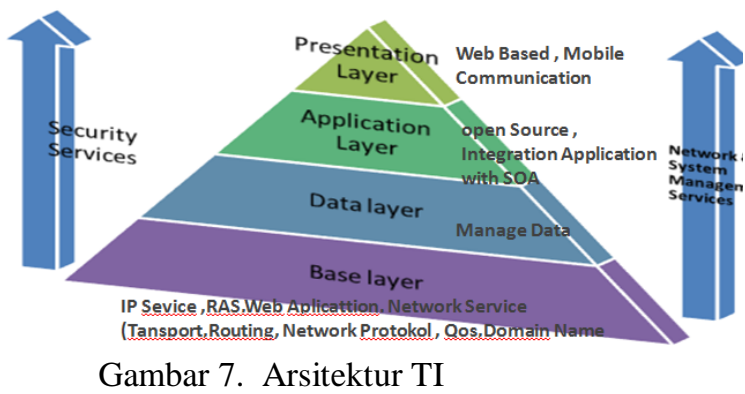

\section{Usulan Infrastruktur Jaringan TI}

Rekomendasi infrastruktur jaringan TI yang diusulkan untuk peningkatan proses bisnis yang ada di Uniba dengan desain infrastruktur arsitektur Jaringan IT.

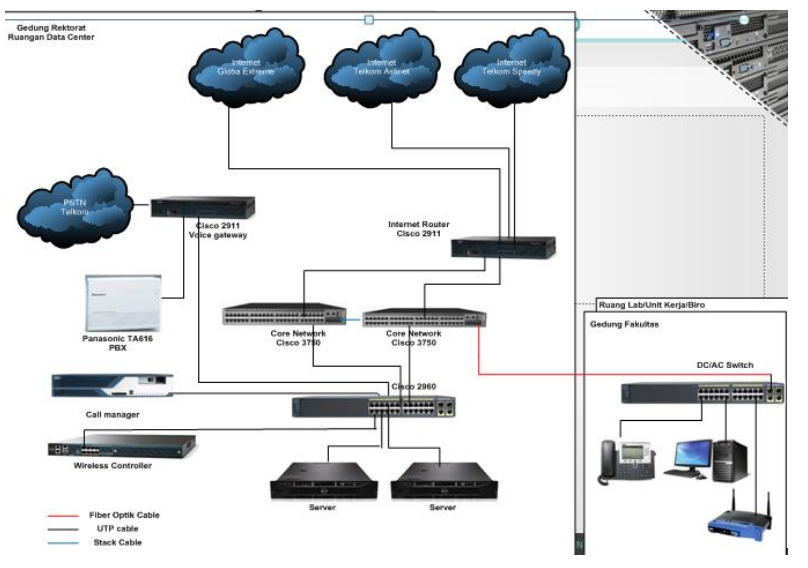

Gambar 8. Usulan Infrastruktur Jaringan

\section{Perencanaan Strategi Manajemen SI/TI}

Setelah membuat usulan perencanaan strategi SI/TI, lalu dirancang usulan teknologi yang akan mendukung perencanaan strategi SI/TI pada Universitas Balikpapan kedepannya nanti. Penerapan teknologi yang ada juga perlu didukung oleh SDM TI yang berkompeten dibidangnya, dengan adanya sistem teknologi yang baru dan SDM yang memadai dapat menjadi jaminan untuk meningkatkan proses bisnis sehingga dapat meningkatkan pelayanan pada unit-unit kerja di Universitas Balikpapan.

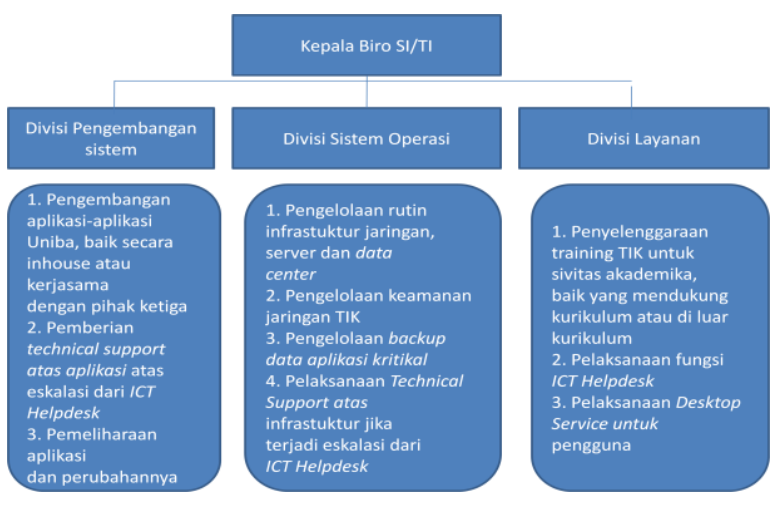

Gambar 9. Usulan Divisi SDM SI/TI Uniba

\section{Prioritas Perencanaan Pengembangan SI/TI}

Prioritisasi memperlihatkan hubungan antara dampak bisnis potensial yang diakibatkan oleh sebuah proyek, dengan kompleksitas dan biaya pelaksanaan proyek, juga pertimbangan tingkat urgensi berdasarkan pertimbangan waktu.

Tabel 3. Tabel penentuan skala priorities

\begin{tabular}{|c|c|c|}
\hline ASPEK & PENJELASAN & LEVELLING \\
\hline Dampak atas bisnis & Peningkatan efisiensi proses & \multirow{3}{*}{$\begin{array}{l}\text { H-High } \\
\text { M-Medium } \\
\text { L-Low }\end{array}$} \\
\hline Usaha implementasi & $\begin{array}{l}\text { Kompleksitas sistem yang } \\
\text { diimplementasi } \\
\text { Hambatan dari sisi teknologi } \\
\text { Ketrampilan SDM yang terlibat }\end{array}$ & \\
\hline Ukuran & Estima si biaya yang dibutuhkan & \\
\hline Urgensi & $\begin{array}{l}\text { Tingkat urgensi eksekusi } \\
\text { inisiatif yang dib agi dalam } \\
\text { beberapa rentangjangka waktu }\end{array}$ & $\begin{array}{l}\text { Pendek (1-2 tahun) } \\
\text { Menengah(3-4 tahun) } \\
\text { Panjang (5 tahun }\end{array}$ \\
\hline
\end{tabular}




\section{Implementasi Pengembangan SI/TI}

Tabel 4. Perencanaan Implementasi Pengembangan

SI/TI
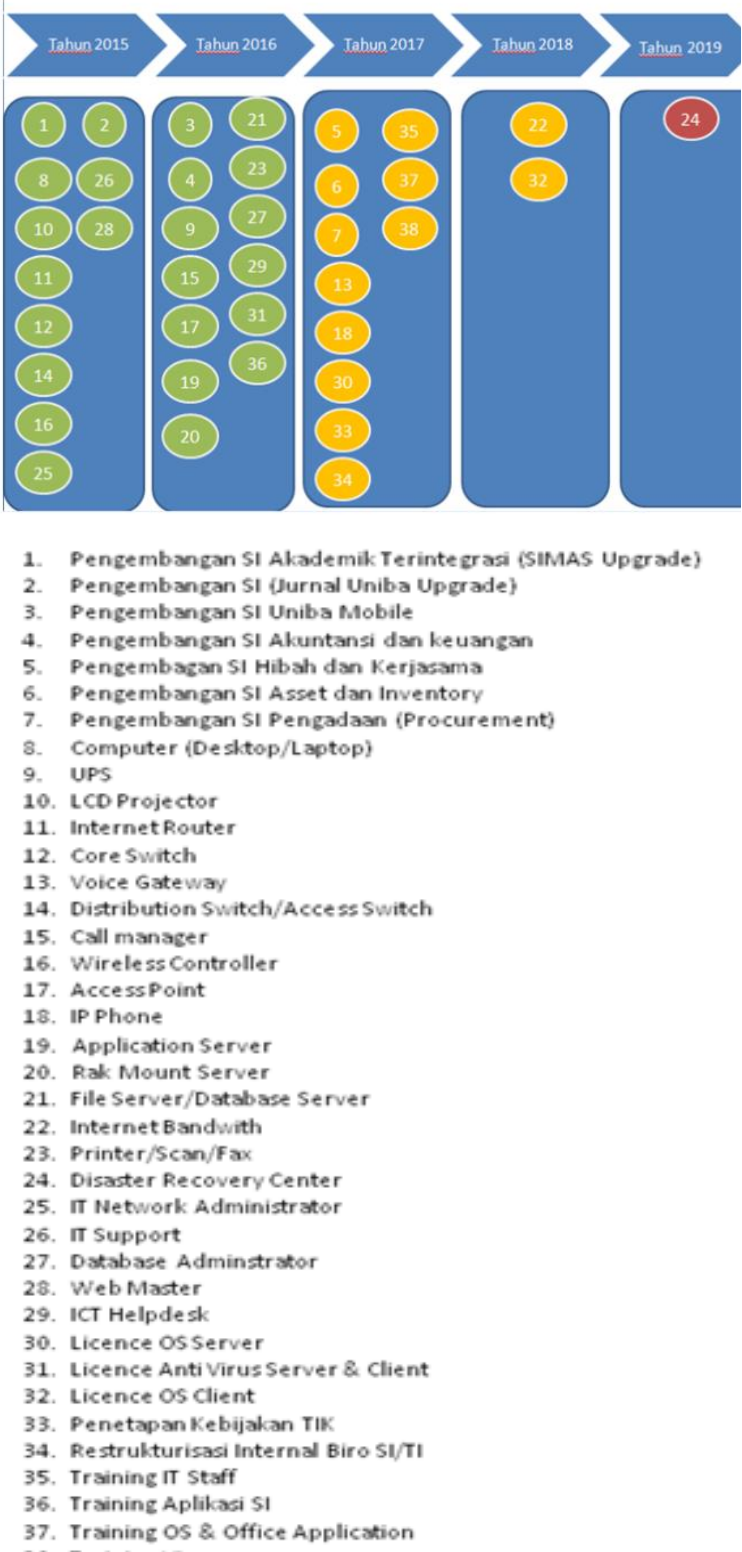

\section{Kesimpulan}

Dari hasil analisa dan pembahasan perancangan strategis SI/TI pada Universitas Balikpapan, maka dapat ditarik kesimpulan sebagai berikut :

1. Perencanaan Strategis SI/TI pada Universitas Balikpapan yang mencakup : Strategi TI, Strategi SI, Strategi Manajemen SI/TI. Ketiga strategi tersebut menghasilkan usulan portfolio aplikasi \& usulan teknologi (hardware, software, dan network infrastructure). Dari setiap strategi yang digunakan dilakukan dengan proses analisa berdasarkan faktor internal \& eksternal organisasi serta faktor internal \& eksternal SI/TI organisasi.

2. Berdasarkan hasil analisis faktor lingkungan internal dan lingkungan eksternal yang ada pada matriks SWOT, Universitas Balikpapan berada pada kuadran II $(0.172$, 0.156), yang berarti pada posisi tersebut telah menempatkan Universitas Balikpapan pada Kuadran II, oleh karena itu strategi yang diambil adalah "Mendukung Strategi Diversifikasi” dimana Universitas Balikpapan dalam penerapan SI/TI nya diharapkan Uniba dapat segera memperbanyak ragam strategi taktisnya3. Perencanaan strategis SI/TI Universitas Balikpapan yang disusun dalam penelitian ini menjadi acuan bagi pengembangan SI/TI dalam menunjang proses bisnis yang ada di Universitas Balikpapan.

\section{Saran}

Adapun saran-saran yang dapat diberikan pada perusahaan dan penelitian selanjutnya adalah sebagai berikut :

1. Komitmen dari pihak manajemen Universitas Balikpapan sangat penting implementasi Perencanaan Strategis SI/TI di Universitas Balikpapan dapat berjalan dengan baik.

2. Strategi IT yang akan diimplementasikan, akan menyebabkan terjadinya perubahan terhadap proses kerja dan kultur sebuah universitas, sehingga diperlukan keterlibatan seluruh civitas akademika di universitas, baik Biro 
SI/IT maupun Biro lainnya dalam pelaksanaan strategi IT.

3. Biro SI/IT perlu membuat kebijakan dan standarisasi pelayanan SI/IT terhadap unit lain untuk menjaga dan meningkatkan kualitas pelayanan, sehingga diperlukan Service Level Agreement (SLA) untuk setiap pelayanan SI/IT.

\section{Daftar Pustaka}

Anita Cassidy, (2006), A practical guide to information systems strategic planning : Second Edition, NewYork : Auerbach Publications.

Benson, R.J., Bugnitz, T.L., Walton, W.B. (2004), From Business Strategy To IT Action: Right Decisions For A Better Bottom Line, New Jersey : John Wiley \& Sons, Inc.
Cassidy, A., 2006, “A Practical Guide to Information Systems Strategic Planning", 2nd edition, Taylor and Francis Group: Boca Rato.

Tozer, Edwin. E., (1996), Strategic IS/IT Planning. Butterworth-Heinemann, USA.

Ward, J. \& Peppard, J. (2002), Strategic planning for Information Systems, $3^{\text {rd }}$. England : John Willey \& Sons, Ltd, West Sussex. 